\title{
Removal of Organic, Nitrogen and Phosphate Pollutants from Slaughterhouse Effluent by a Process Combining Biodegradation with Adsorption
}

\author{
Weldi Gnowe Djonga ${ }^{1,2}$, Eric Noubissié ${ }^{1, ~}$, Guy Bertrand Noumi \\ ${ }^{1}$ Department of Chemical Engineering, University Institute of Technology, Ngaoundere, Cameroon \\ ${ }^{2}$ Department of Chemistry, University of Ngaoundere, Ngaoundere, Cameroon \\ Email address: \\ djongaweldignowe@yahoo.com (W. G. Djonga), noubissieerik@yahoo.fr (E. Noubissié), eric.noubissie@univ-pau.fr (E. Noubissié), \\ gnoumi@yahoo.fr (G. B. Noumi) \\ ${ }^{*}$ Corresponding author
}

\section{To cite this article:}

Weldi Gnowe Djonga, Eric Noubissié, Guy Bertrand Noumi. Removal of Organic, Nitrogen and Phosphate Pollutants from Slaughterhouse Effluent by a Process Combining Biodegradation with Adsorption. Journal of Energy, Environmental \& Chemical Engineering.

Vol. 6, No. 2, 2021, pp. 31-36. doi: 10.11648/j.jeece.20210602.11

Received: April 30, 2021; Accepted: May 20, 2021; Published: May 27, 2021

\begin{abstract}
Improving the efficiency of slaughterhouse effluent treatment processes is an ongoing quest. The objective of this work is to assess the efficiency of the treatment process, combining biodegradation and adsorption, on the elimination of organic, nitrogen and phosphate loads contained in the slaughterhouse effluent. To achieve this, a slaughterhouse effluent was sampled in the town of Ngaoundéré (Cameroon). after characterization, it was then introduced into two reactors operating in batch and with stirring, with the adsorbent produced based on sawdust of Triplochyton scleroxylon (Ayous). One of the reactors operated in the absence of oxygen (anoxia) and the other in the presence of oxygen (aeration). Then the effluent was characterized daily during the five-day treatment. The results obtained show that the $\mathrm{pH}$ of the effluent varies between 6.5 and 8 in the two reactors during the treatment. an oxygenating effect of the environment was observed both on the elimination of organic matter and on that of nitrogen pollution. Turbidity reduction rates vary from $77.3 \%$ in anoxia to $94 \%$ in aeration at the end of the five days of treatment. This process, which combines biodegradation with adsorption, reduces the biological treatment time of slaughterhouse effluent from more than 3 weeks to 2 days, with satisfactory efficiency in removing organic and nitrogen loads.
\end{abstract}

Keywords: Slaughterhouse Effluent, Combined Treatment Process, Biodegradation, Anoxia, Oxygenation, Adsorption, Nitrogen, Organic Matter

\section{Introduction}

Several industrial activities use large quantities of water and generate as much in the form of effluent. Slaughterhouses are a case in point, where most of the water is used for cleaning the plant. But the wastewater that comes out is highly loaded with organic matter, nitrogen and phosphate [1]. The discharge of this wastewater without prior treatment constitutes a source of pollution for the environment with significant consequences on the social life of living beings. The phosphates and nitrates contained in this wastewater are, for example, the main cause of eutrophication in lakes and slow-flowing rivers [2]. The high
OM loads responsible for the turbidity of the water are at the origin of the suffocation of aquatic animals in the receiving environment $[2,3]$. These pollutant loads also create favourable conditions for the proliferation of mosquitoes and odours that are often the cause of public health problems. It is to prevent all these environmental and social consequences that it is essential to treat these effluents before they are released into nature.

There are various more or less efficient processes for treating slaughterhouse effluents. There are physical, chemical and biological treatments $[4,5]$. Given the characteristics of the pollutant load of slaughterhouse effluents, biological treatment, the principle of which is 
based on microbial biodegradation, is the most appropriate [6-9]. However, this biological treatment has limitations related not only to the effectiveness but also to the residence time, which is more or less long. With a view to correcting these limits, we thought of testing a process combining biodegradation and adsorption. To achieve this, it was necessary to assess the level of efficiency of the adsorption on the removal of certain pollutants contained in the slaughterhouse effluent. This objective has been explored by Djonga et al., $[10,11]$ with satisfactory results. In 2020, these same authors studied the influence of oxygenation on the biodegradation of the pollutants contained in this effluent. They showed that there is a minimum effective biological treatment time (9/27 days), beyond which biodegradation of pollutants is practically negligible [1]. However, this minimum effective biodegradation time has an average rate of $<80 \%$. With more than 15 days of treatment gained as a result of this work, the problem of the long biological treatment time has found a solution. All that remains is to improve efficiency. This is what justifies the idea of combining this biological treatment with adsorption. One of the objectives of the work of $[10,11]$ was also to test the effectiveness of adsorbents made from sawdust of several species of wood. As a result of this work, the Triplochyton scleroxylon based adsorbent (Ayous) showed very interesting results. This is what justifies its use in this work.

\section{Material and Methods}

\subsection{Sampling and Characterization of the Slaughterhouse Effluent}

The effluent was collected from a slaughterhouse in the city of Ngaoundéré which can be located according to the following geographic coordinates $\left(7^{\circ} 19^{\prime} 58^{\prime}\right.$ N $; 1^{\circ} 34^{\prime} 11^{\prime \prime} \mathrm{E}$; $1110 \mathrm{~m})$. It is an establishment which slaughters more than twenty cattle per day. The sample was transported to the laboratory and stored at $4^{\circ} \mathrm{C}$. It underwent a physicochemical characterization before and after treatment. Five parameters were mainly followed during the characterization. This is the organic matter which was determined according to the method implemented by Rodier [12]. The nitrogenous forms of $\mathrm{NH}_{4}^{+}, \mathrm{NO}_{2}^{-}$and $\mathrm{NO}_{3}{ }^{-}$were determined according to the methods of Rodier [13]. The phosphates were determined according to the method of Rodier et al. [14]. Turbidity was measured using a Hanna brand turbidimeter. The characterized sample was subjected to the treatment process combining biodegradation with adsorption.

\subsection{Adsorbent Used in the Combination Treatment Process}

The adsorbent used in this work was produced on the basis of sawdust from Triplochyton scleroxylon (Ayous). It was produced and characterized by Djonga et al. [10]. Its characteristics are presented in Table 1.

Table 1. Characteristics of adsorbent from Triplochyton scleroxylon.

\begin{tabular}{|c|c|c|c|c|}
\hline pH & $I_{\text {iodine }}(\mathrm{mg} / \mathrm{g})$ & $\mathrm{I}_{\mathrm{BM}}(\mathrm{mg} / \mathrm{g})$ & $\mathrm{S}_{\mathrm{BM}}\left(\mathrm{m}^{2} / \mathrm{g}\right)$ & \\
\hline 4.3 & $758 \pm 8$ & $9.52 \pm 0.05$ & 69.56 & \\
\hline \multicolumn{5}{|c|}{ Different surface functions of the adsorbent } \\
\hline $\begin{array}{l}\text { Carboxylic groups }(\mathrm{meq} / \mathrm{g}) \\
0.000\end{array}$ & $\begin{array}{l}\text { Lactone groups }(\mathrm{meq} / \mathrm{g}) \\
0.003\end{array}$ & $\begin{array}{l}\text { Phenolic acidity (meq/g) } \\
0.162\end{array}$ & $\begin{array}{l}\text { Total acidity }(\mathrm{meq} / \mathrm{g}) \\
0.164\end{array}$ & $\begin{array}{l}\text { Basic groups }(\mathrm{meq} / \mathrm{g}) \\
0.000\end{array}$ \\
\hline
\end{tabular}

(Djonga et al., [10].

\subsection{Slaughterhouse Effluent Treatment Trial by the Process Combining Biodegradation with Adsorption}

The treatment process combining biodegradation with adsorption was carried out in two reactors operating in batch with stirring. One of the two reactors operated in the absence of oxygen (anoxia) and the other in the presence of oxygen (aeration) according to the diagram of the experimental setup shown in Figure 1.

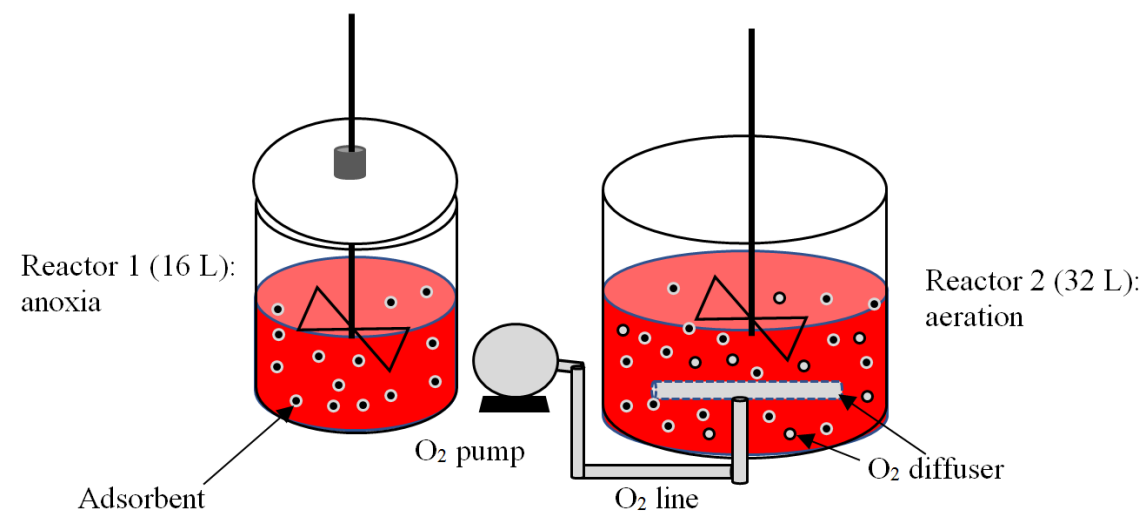

Figure 1. Experimental device of the slaughterhouse effluent treatment process, combining biodegradation with adsorption.

The slaughterhouse effluent was diluted to $100^{\text {th }}$ and 16 liters were introduced into reactor 1 (R1) which operated in anoxia. 32 liters of the diluted effluent were introduced into reactor 2 (R2) which operated with aeration. The aeration reactor was supplied with oxygen using a pump injecting 1.6 $\mathrm{kg}$ of $\mathrm{O}_{2} / \mathrm{h}$ for 12 hours per day. Then the adsorbent was 
introduced into each reactor at a ratio of $2 \mathrm{~g} / \mathrm{L}$. This amount of adsorbent corresponds to the minimum and effective amount for adsorption, obtained by Djonga et al., [10]. The contents of the two reactors were stirred at $100 \mathrm{rpm}$. Processing took place at room temperature $\left(23-25^{\circ} \mathrm{C}\right)$ and the $\mathrm{pH}$ of the slaughterhouse effluent. In order to assess the efficiency of the process combining biodegradation with adsorption, the effluent under treatment was characterized every day during five days. During these five days, it was specifically a question of following the kinetics of elimination of organic, nitrogen and phosphate charges. Thus, organic matter was determined according to the method of
Rodier [12], $\mathrm{NH}_{4}^{+}, \mathrm{NO}_{2}^{-}$and $\mathrm{NO}_{3}^{-}$were determined according to the methods of Rodier [13] and phosphates according to the method of Rodier et al., [14].

\section{Results}

\subsection{Characteristics of the Slaughterhouse Effluent to Be Treated}

Table 2 shows the physicochemical characteristics of the slaughterhouse effluent to be treated.

Table 2. Physicochemical characteristics of the slaughterhouse effluent to be treated.

\begin{tabular}{lll}
\hline Parameters & Raw slaughterhouse effluent & Cameroonian standards for discharges (MNEPDED) \\
\hline $\mathrm{pH}$ & $7.18 \pm 0,02$ & $6-9$ \\
$\mathrm{E} \mathrm{Cond}(\mu \mathrm{S} / \mathrm{cm})$ & $2692 \pm 100$ & $/$ \\
Turbidity $(\mathrm{NTU})$ & $6167 \pm 24$ & $/$ \\
$\mathrm{OM}(\mathrm{mg} \mathrm{O} / \mathrm{L})$ & $1613 \pm 12$ & $\leq 30$ \\
$\mathrm{NH}_{4}{ }^{+}(\mathrm{mg} / \mathrm{L})$ & $7579 \pm 127$ & $/$ \\
$\mathrm{NO}_{2}^{-}(\mathrm{mg} / \mathrm{L})$ & $12.8 \pm 0,1$ & 20 \\
$\mathrm{NO}_{3}^{-}(\mathrm{mg} / \mathrm{L})$ & $305 \pm 53$ & $\leq 10$ \\
$\mathrm{PO}_{4}{ }^{-}(\mathrm{mg} / \mathrm{L})$ & $453 \pm 22$ & \\
\hline
\end{tabular}

$\mathrm{OM}=$ organic matter; $\mathrm{E}$ Cond $=$ electrical conductivity.

These results show that the slaughterhouse effluent to be treated is slightly basic. It is, however, very conductive and turbid. It is also very loaded with nitrogenous and organic compounds. Ammonium alone represents more than $80 \%$ of the nitrogen pollution of this effluent. The high load of organic matter in this effluent justifies the high turbidity. Overall, its organic, nitrogen and phosphate loads are significantly high compared to Cameroonian standards for the discharge of treated wastewater.

\subsection{Evolution of Physico-chemical Parameters During Treatment}

\subsubsection{Evolution of $\mathrm{pH}$, Turbidity and Organic Matter}

Figure 2 shows the change in the $\mathrm{pH}$ of the effluent during the treatment combining biodegradation and adsorption in anoxia and aeration.

(a) Anoxia

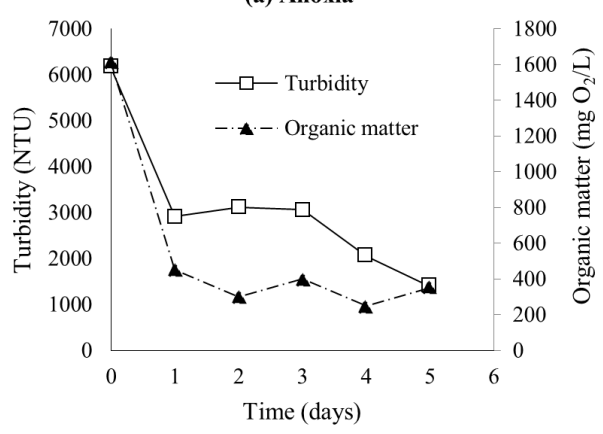

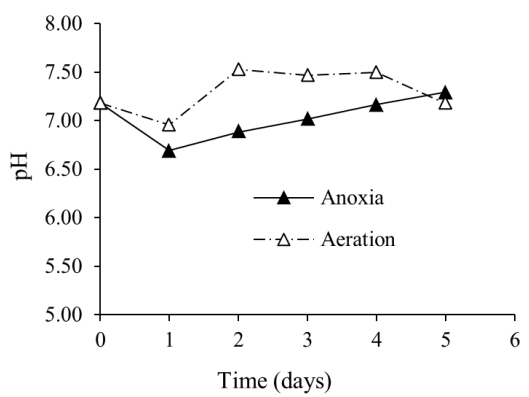

Figure 2. Evolution of the pH of the effluent during the combined treatment.

These results show that the $\mathrm{pH}$ varies little (6.7 and 7.5) throughout the treatment, whether in anoxia or in aeration. Figure 3 shows the evolution of turbidity and organic matter in the effluent during the treatment combining biodegradation and adsorption in anoxia and aeration.

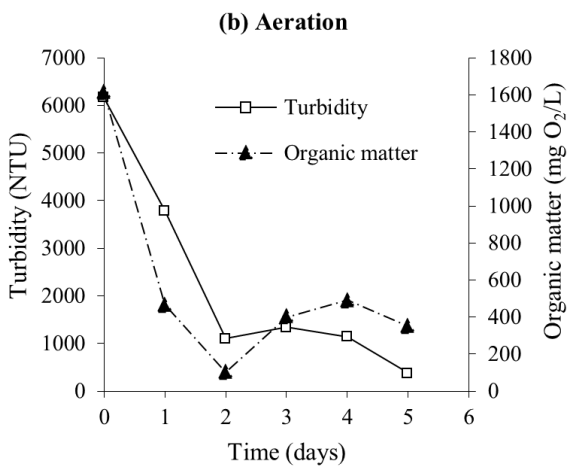

Figure 3. Evolution of turbidity and organic matter during the combined treatment (biodegradation and adsorption) in anoxia (a) and in aeration (b).

This result shows a significant decrease in turbidity and organic matter $(\mathrm{OM})$ over treatment. These two parameters are related by the influence of one on the other. This is what justifies the almost similar paces of their evolution curves. An oxygenating effect of the medium is noticeable both on the duration of the treatment and on the effectiveness of the 
treatment. This oxygenation effect is clearly seen through the turbidity reduction rates, which vary from $77.3 \%$ in anoxia to $94 \%$ in aeration at the end of the five days of treatment. This oxygenation effect was even noticeable at the end of the $2^{\text {nd }}$ day of treatment when the OM reduction rates already varied from $81.4 \%$ in anoxia to $94 \%$ in aeration. Likewise, those for turbidity vary from $49.4 \%$ in anoxia to $82 \%$ in aeration at the

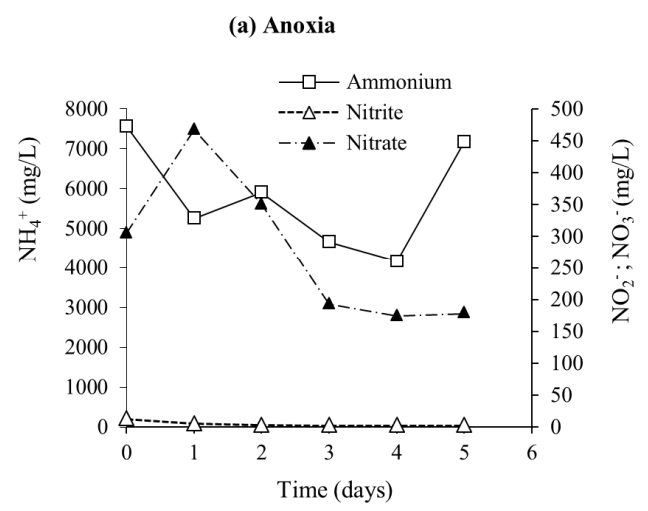

end of the $2^{\text {nd }}$ day of treatment.

\subsubsection{Evolution of Nitrogen Pollutants}

Figure 4 shows the evolution of the elimination of three forms of nitrogen followed $\left(\mathrm{NH}_{4}{ }^{+}, \mathrm{NO}_{2}{ }^{-}\right.$and $\left.\mathrm{NO}_{3}{ }^{-}\right)$during the treatment combining biodegradation and adsorption in the presence and absence of oxygen.

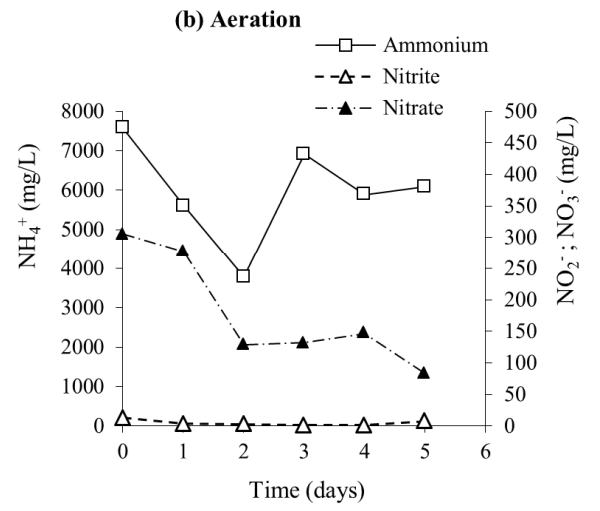

Figure 4. Evolution of ammonium, nitrite and nitrate during the combined treatment (biodegradation and adsorption) in anoxia (a) and in aeration (b).

Figure 4 shows that the ammonium, nitrite and nitrate contained in the slaughterhouse effluent are generally removed in two phases. The $1^{\text {st }}$ phase goes from the $1^{\text {st }}$ to the $3^{\text {rd }}$ day of treatment in the anoxia tank, and from the $1^{\text {st }}$ to the $2^{\text {nd }}$ day of treatment in the aeration phase. This $1^{\text {st }}$ phase is characterized by a significant decrease in the concentration of the three nitrogenous pollutants in the effluent. During this phase, the reduction rates vary from 38.5 to $50.1 \%$ for $\mathrm{NH}_{4}^{+}$, 37 to $29.1 \%$ for $\mathrm{NO}_{3}^{-}$and 84.6 to $84.6 \%$ for $\mathrm{NO}_{2}^{-}$, in anoxia and in aeration respectively. The $2^{\text {nd }}$ phase, which is characterized in some by a slight decrease in concentration $\left(\mathrm{NO}_{3}{ }^{-}\right)$, in others by a slight re-increase in concentration $\left(\mathrm{NH}_{4}^{+}\right.$and $\left.\mathrm{NO}_{2}{ }^{-}\right)$, goes from the $2^{\text {nd }}$ to the 5th day of treatment. This observation highlights the effect of oxygenating the medium on the efficiency and duration of treatment specific to the elimination of nitrogenous pollutants.

\subsubsection{Evolution of Phosphates}

Figure 5 shows the evolution of the elimination of phosphates $\left(\mathrm{PO}_{4}{ }^{3-}\right)$ contained in the slaughterhouse effluent during treatment combining biodegradation and adsorption in the presence and absence of oxygen

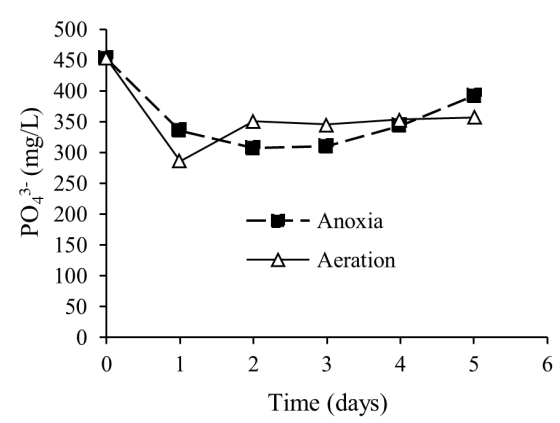

Figure 5. Evolution of phosphate during the combined treatment (biodegradation and adsorption).
This result shows a low removal of phosphates by the process combining biodegradation and adsorption in anoxia and aeration. The maximum reduction rate in anoxia is $32 \%$ obtained after 2 days of treatment while it is $37 \%$ after 1 day of treatment with aeration. The observed oxygenation effect on the removal of phosphates by this process is only useful over the duration of treatment. Because on this specific aspect, this result agrees with those of Figures 2 and 3 to show the significantly positive influence on the oxygenation of the medium on the reduction of the processing time of the slaughterhouse effluent.

\section{Discussion}

\subsection{Effect of $\mathrm{pH}$ on the Efficiency of the Process Combining Biodegradation with Adsorption}

The $\mathrm{pH}$ of the effluent changed very little during its treatment in the two reactors. It remained favourable for the development of microorganisms responsible for the biodegradation of organic, nitrogen and phosphate loads contained in the effluent. Indeed, the development of microorganisms during biological treatment is favourable in the $\mathrm{pH}$ range between 6 and 9 [15]. This $\mathrm{pH}$ range observed during treatment also implies more or less favourable adsorption of organic matter and cationic pollutants such as ammonium; especially since the zero charge point of the adsorbent used is 4.3 (Table 2). This means that in a $\mathrm{pH}$ range of the effluent between 6 and 8 as it is the case here, the surface of the adsorbent is predominated by the negative charge, therefore favourable for adsorbing the positively charged compounds.

\subsection{Efficiency of the Process Combining Biodegradation and Adsorption on the Elimination of Organic Matter}

The results in Figure 3 showed significant elimination of 
turbidity and OM from the effluent during the five days of treatment in both anoxia and aeration. The high turbidity of the effluent to be treated is mainly due to the presence of OM characterized by bovine red blood cells. This relationship, which exists between turbidity and OM, justifies the almost similar evolution of their eliminations in the effluent. Thus, the removal of OM from the effluent will automatically result in the removal of its turbidity. Here, the elimination of OM is due to the combined action of microorganisms (biodegradation) and the adsorbent (adsorption). This elimination is significantly greater in the presence of oxygen than in the absence of oxygen. These results are in agreement with those of Djonga et al., [1] who already showed the positive influence of oxygenation of the medium on the rate of biodegradation of OM. however, they stated that oxygenation of the medium accelerated biodegradation without increasing the efficiency of its removal. The efficiency aspect of OM removal was therefore corrected in this process by its retention on the adsorbent introduced into the reactors. Compared to the work of Djonga et al., [1], adsorption reduced the time required for $\mathrm{OM}$ elimination, from 9 days of treatment offered by biological treatment alone, to 2 days when combined with adsorption.

\subsection{Efficiency of the Process Combining Biodegradation and Adsorption on the Elimination of Nitrogen Pollutants}

The elimination of nitrogen pollutants during the treatment combining biodegradation with adsorption takes place in two phases. The $1^{\text {st }}$ phase, which runs from the $1^{\text {st }}$ to the $3^{\text {rd }}$ day of treatment in anoxia, is characterized by the significant decrease in the concentration of the three nitrogenous pollutants in the effluent. Indeed, during these three days of anoxia treatment, it grows cumulatively phenomena nitrification (biodegradation) and adsorption of ammonium. This leads to a decrease in the concentrations of ammonium, nitrate and nitrite in the effluent. The brief increase in nitrates observed at the end of the $1^{\text {st }}$ day of treatment is explained by the successive phenomena of nitrification of ammonium to nitrate, and nitration of nitrites to nitrates, before being reduced to $\mathrm{N}_{2}$ during the $2^{\text {nd }}$ and $3^{\text {rd }}$ day of treatment [1]. However, there is a $2^{\text {nd }}$ phase of treatment in anoxia which goes from the $3^{\text {rd }}$ to the $5^{\text {th }}$ day. This phase is characterized by an increase in ammonium in the effluent. This increase can be attributed to the release of organic matter (Figure 3a) whose ammonification (biodegradation) by heterotrophic microorganisms, contributes to the release of ammonium in the effluent.

The aeration treatment also shows removal of ammonium, nitrite and nitrate which takes place more or less in two phases. The $1^{\text {st }}$ phase, which takes place over 2 days, is characterized by a significant decrease in the concentration of nitrogen pollutants in the effluent. The removal of $\mathrm{NH}_{4}{ }^{+}$is certainly due to the combined action of biodegradation (autotrophic microorganisms) and adsorption on the adsorbent introduced into the reactor. That of $\mathrm{NO}_{3}^{-}$and $\mathrm{NO}_{2}^{-}$is due to denitrification on the one hand and their adsorption to the adsorbent on the other hand. The reduction of $\mathrm{NO}_{3}{ }^{-}$to $\mathrm{N}_{2}$ by passing through the intermediate $\mathrm{NO}_{2}^{-}$contributes to the reduction of the $\mathrm{NO}_{3}{ }^{-}$ concentration in the medium, and should therefore not be neglected [16]. The $2^{\text {nd }}$ phase, which takes place during the last three days, is generally characterized by the increase of the three forms of nitrogen in the effluent. The increase in $\mathrm{NH}_{4}{ }^{+}$is probably due to the increase by release of $\mathrm{OM}$ (Figure 3b), the ammonification of which led to the release of $\mathrm{NH}_{4}{ }^{+}$in the effluent. Once available in the medium, part of this $\mathrm{NH}_{4}^{+}$undergoes a succession of oxidation, first in $\mathrm{NO}_{2}{ }^{-}$by nitritation, then in $\mathrm{NO}_{3}{ }^{-}$by nitration, favoured by oxygenation of the medium [1]. It is the development of these last two phenomena which explains the slight decrease in $\mathrm{NO}_{3}^{-}$and the slight increase in $\mathrm{NO}_{2}^{-}$during this $2^{\text {nd }}$ phase of treatment with ventilation (Figure $4 \mathrm{~b}$ ). However, it is important to note the absence of the accumulation of $\mathrm{NO}_{3}^{-}$in the effluent during treatment, which was a limitation of biological treatment alone [1]. This accumulation of $\mathrm{NO}_{3}^{-}$was avoided by the permanent adsorption of $\mathrm{NH}_{4}^{+}$, initially present in the effluent or generated later by ammonification of OM.

These results show that, despite these fluctuations in the concentrations of nitrogen pollutants in the effluent during the anoxia and aeration treatments, the introduction of the adsorbent into the reactors made it possible to reduce the treatment time from 9 to 2 days, compared to biological treatment alone [1]. The introduction of the adsorbent also made it possible to increase the efficiency of the removal of these nitrogenous pollutants, in particular through the removal of nitrates which accumulated in the effluent during biological treatment alone [1].

\section{Conclusion}

This work was about assessing the efficiency of the slaughterhouse effluent treatment process, combining biodegradation and adsorption, on the removal of organic, nitrogen and phosphate loads. It emerges from this work that the natural $\mathrm{pH}$ of the effluent during treatment is as favourable to microbial activity as to the absorption of cationic pollutants including ammonium present in the effluent. The combination of the factors such as the oxygenation of the medium and the introduction of the adsorbent into the reactor, promotes both the rate of biodegradation of organic matter and the efficiency of its removal. The absorption of ammonium (cationic pollutant) initially present in the effluent, or that which was generated by ammonification of $\mathrm{OM}$, has a significantly positive impact on the removal of nitrates. The process developed in this work, which combines biodegradation with adsorption, does not improve the removal efficiency of phosphates from slaughterhouse effluent. However, it has satisfactory efficiency in removing organic and nitrogen fillers, and it makes it possible to reduce the biological treatment time of this effluent from more than 3 weeks to 2 days. 


\section{Acknowledgements}

The authors of this work address their gratitude to Prof. ALI Ahmed, Head of Department of Chemical Engineering and Responsible of the Laboratory of Chemical Engineering and Environment of the University Institute of Technology (IUT) of Ngaoundéré. Thank you to the Department of Chemistry of the Faculty of Sciences of the University of Ngaoundéré in Cameroon.

\section{References}

[1] Djonga G. W., Noubissié E., Noumi G. B. (2020). Influence of time and oxygenation on the degradation of organic matter, nitrogen and phosphates during the biological treatment of slaughterhouse effluent. Case Studies in Chemical and Environmental Engineering. 2.290 pp. https://doi.org/10.1016/j.cscee.2020.100048.

[2] Ge H., Batstone D. J., Keller J. (2013). Operating aerobic wastewater treatment at very short sludge ages enables treatment and energy recovery through anaerobic sludge digestion. Water research. 47. 6546 - 6557. http://dx.doi.org/10.1016/j.watres.2013.08.017.

[3] Lemaire R., Yuan Z., Bernet N., Marcos M., Yilmaz G., Keller J. (2008). A sequencing batch reactor system for high-level biological nitrogen and phosphorus removal from abattoir wastewater. Biodegradation. 20 (3). 339-350. http://doi:10.1007/s10532-008-9225-z.

[4] Khennoussi A., Chaouch M., Chahlaoui A. (2013). Traitement des effluents d'abattoir de viande rouge par électrocoagulation-flottation avec des électrodes en fer. Revue des sciences de l'eau. 26 (2). 135-150. https://doi.org/10.7202/1016064ar.

[5] Raed S. A., Alaa K. M., Samar R. H., Israa E. A., Shimaa R. H. (2019). A pilot model for slaughterhouse wastewater treatment using moringa oleifera seed husks, pods and extract followed by aeration. Journal of Engineering and Applied Sciences 14 (2): 354-362.

[6] Lemaire R., Meyer R., Taske A., Crocetti G. R., Keller J., Yuan Z. (2006). Identifying causes for $\mathrm{N}_{2} \mathrm{O}$ accumulation in a lab-scale sequencing batch reactor performing simultaneous nitrification, denitrification and phosphorus removal. Journal $\begin{array}{llll}\text { of } & \text { Biotechnology } & 122 & 62-72 .\end{array}$ http://doi:10.1016/j.jbiotec.2005.08.024.
[7] Keller J., Watts S., Battye-Smith W., Chong R. (2001). Fullscale demonstration of biological nutrient removal in a single tank SBR process, Water Sci. Technol. 43 355-362, https://doi.org/10.2166/wst.2001.0157.

[8] Baker B. R., Mohamed R., Al-Gheethi A., Aziz H. A. (2020). Advanced technologies for poultry slaughterhouse wastewater treatment: A systematic review. Journal of Dispersion Science and Technology. 1-20. https://doi.org/10.1080/01932691.2020.1721007.

[9] Musa M. A., Idrus S., Harun M. R., Marzuki T. F. T. M., Wahab A. M. A. (2020). A comparative study of biogas production from cattle slaughterhouse wastewater using conventional and modified upflow anaerobic sludge blanket (UASB) reactors, Int. J. Environ. Res. Publ. Health 17 (283): 1-19. https://doi.org/10.3390/ijerph17010283.

[10] Djonga G. W., Noubissié E., Samomssa I., Noumi G. B. (2019). Discolouration Studies of the Slaughterhouse Effluent by Adsorption on Two Adsorbents Made from Species Sawdust of Triplochiton scleroxilon and Milicia excels. Environmental Management and Sustainable Development. 8 (3). 38 - 57. https://doi:10.5296/emsd.v8i3.15000.

[11] Djonga G. W., Noubissié E. Noumi G. B. (2019). Discoloration test of a slaughterhouse effluent by adsorption on two adsorbents produced from sawdust of Khaya senegalensis and Pinus sp. Results in Engineering 4: 1-8. https://doi.org/10.1016/j.rineng.2019.100068.

[12] Rodier J. (2005) L'analyse de l'eau, eaux naturelles, eaux résiduaires et eaux de mer. $8^{\text {ème }}$ Edition, Dunod Paris.

[13] Rodier J. (1978) L'Analyse de l'eau: eaux naturelles, eaux résiduaires, eau de mer. Chimie, physico-chimie, bactériologie, biologie. $6^{\text {ème }}$ Edition, Dunod Paris.

[14] Rodier J., Legube B., Merlet N., et al. (2009) L'analyse de l'eau: eaux naturelles, eaux résiduaires, eaux de mer. $9^{\text {ème }}$ Edition, Dunod Paris.

[15] Gürel L., Büyükgüngör H. (2011). Treatment of slaughterhouse plant wastewater by using a membrane bioreactor. Water Science \& Technology. 64 (1): 214-219 https://doi:10.2166/wst.2011.677.

[16] Philips S., Laanbroek H. J., Verstraete W. (2002). Origin, causes and effects of increased nitrite concentrations in aquatic environments. Environmental Science \& Bio/Technology 1. 115-141. https://doi:10.1023/A:1020892826575. 